\title{
Acute fissuration of a giant splenic artery aneurysm detected by point-of-care ultrasound: case report
}

\author{
Philippe Le Conte ${ }^{1^{*}} \mathbb{D}$, David Trewick${ }^{1}$, Philippe Pes $^{1}$, Eric Frampas ${ }^{2}$, Eric Batard ${ }^{1}$ and Winfocus-France Group
}

\begin{abstract}
Background: Epigastric pain is frequent in Emergency Medicine and remains a challenging situation. Besides benign etiologies such as gastritis or uncomplicated cholelithiasis, it could reveal myocardial infarction or vascular disease. Point-of-care ultrasound (POCUS) could be performed in such situation.

Case presentation: A healthy 66-year-old man with no previous medical history was admitted to the Emergency Department for a rapid onset epigastric pain. He reported taking non-steroidal anti-inflammatories for 1 week prior to admission. His pain had rapidly subsided and the physical examination was inconclusive. ECG and blood samples were normal. POCUS revealed a vascular mass located between the spleen and the left kidney measuring $80 * 74 \mathrm{~mm}$ associated with small amounts of free peritoneal fluid. Computed tomography diagnosed a fissurated giant aneurysm of the splenic artery. The aneurysm was managed emergently by endovascular exclusion by selective splenic artery embolization. The post-intervention course was uneventful and the patient was discharged home 3 days later. The patient has remained free from any complications of the embolization 6 months after the procedure.

Conclusion: Spontaneously regressive epigastric pain with a normal physical and biology/ECG should not necessarily reassure the physician, in particular if patients have cardiovascular risk factors. A POCUS should be considered for these patients.
\end{abstract}

\section{Background}

Epigastric pain is a frequent and often challenging situation in the Emergency Department (ED) [1]. Besides benign etiologies such as gastritis or uncomplicated cholelithiasis, it could reveal myocardial infarction, aortic, or vascular diseases. The risk is neglecting vascular dissection or rupture leading to a possible fatal hemorrhagic shock [2]. Splenic artery aneurysms (SAA) are rare, often asymptomatic, and usually discovered incidentally [3] but remain potentially life threatening lesions [4]. SAA were reported in $0.78 \%$ of 3600 non-selective angiograms [4]; the incidence increases with female gender, in older patients and portal hypertension [5]. The ED incidence was reported as $0.011 \%$ in a retrospective study $[6]$.

\footnotetext{
*Correspondence: philippe.leconte@chu-nantes.fr

1 Service des Urgences, CHU de Nantes, 44093 Nantes, France Full list of author information is available at the end of the article
}

We report a case of a patient consulting in the ED for epigastric pain in whom point-of-care ultrasound (POCUS) revealed an acute fissuration of a giant splenic aneurysm.

\section{Case report}

A healthy 66-year-old man with no previous medical history was admitted to the ED for a first episode of rapid onset severe epigastric pain. It appeared at rest without associated symptoms such as dyspnea or vomiting. $\mathrm{He}$ reported taking non-steroidal anti-inflammatories for 1 week prior to admission for an epicondylitis. On admission, his pain had rapidly subsided and the physical examination was inconclusive: blood pressure, temperature, heart rate, and capillary filling were normal. Thoracic auscultation and abdominal palpation revealed only slight epigastric pain. ECG and troponin assay were normal as was hemoglobin, bilirubin, liver enzymes, and lipase levels. As a part of our department's policy, 
a POCUS was performed essentially to rule out cholelithiasis. It was performed using a Philips CX50 with a 3.5 $-5 \mathrm{MHz}$ abdominal probe. There were no gallstones; however, POCUS revealed a mass located between the spleen and the left kidney (Fig. 1 and Additional file 1: Video 1) measuring $80 * 74 \mathrm{~mm}$. The mass was vascular with a strong color Doppler signal (Fig. 2 and Additional file 2: Video 2) and an intraluminal thrombus which explains why the Doppler signal does not fill all the lumen. The maximum velocity in the aneurysm was only $18 \mathrm{~cm} / \mathrm{s}$ because of the large diameter. The aorta was explored from diaphragm to bifurcation. No other aneurysm was found. Small amounts of free peritoneal fluid were detected around the spleen.

Urgent computed tomography diagnosed a fissurated giant aneurysm of the splenic artery (Figs. 3, 4,

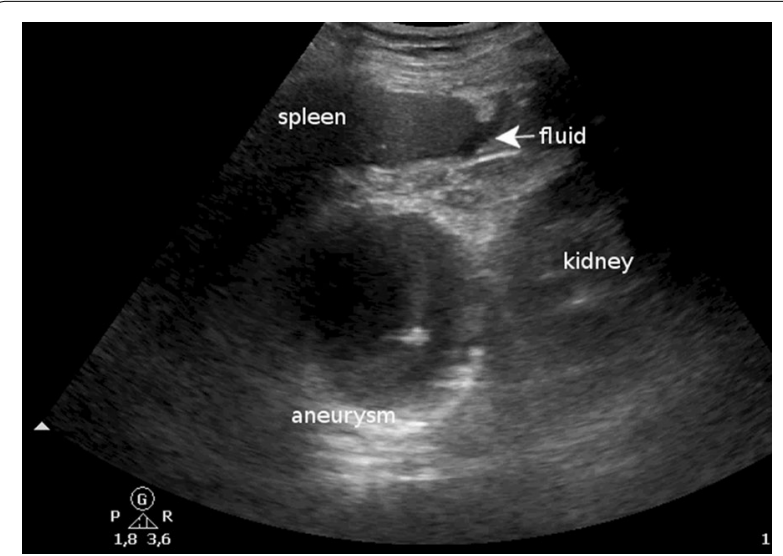

Fig. 1 POCUS scan of the left upper quadrant of a patient presenting with epigastric pain. See the vascular mass located between spleen and kidney

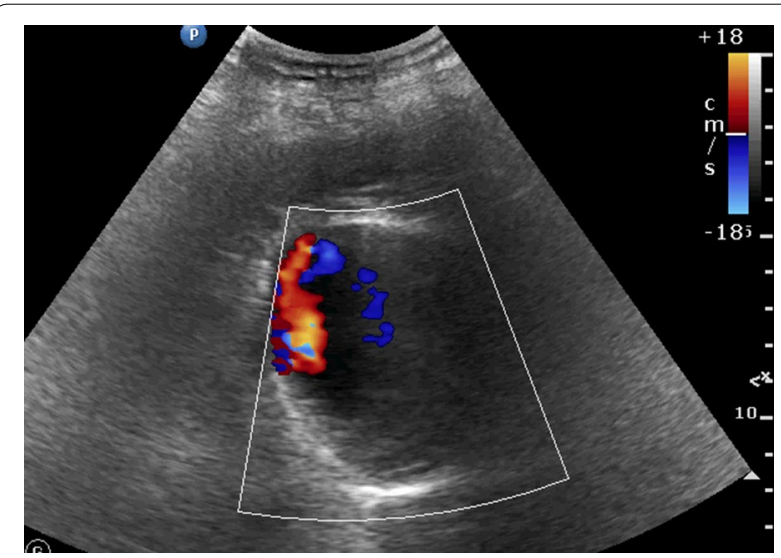

Fig. 2 POCUS color Doppler scan of left upper quadrant in a patient presenting an epigastric pain. See the strong Doppler signal

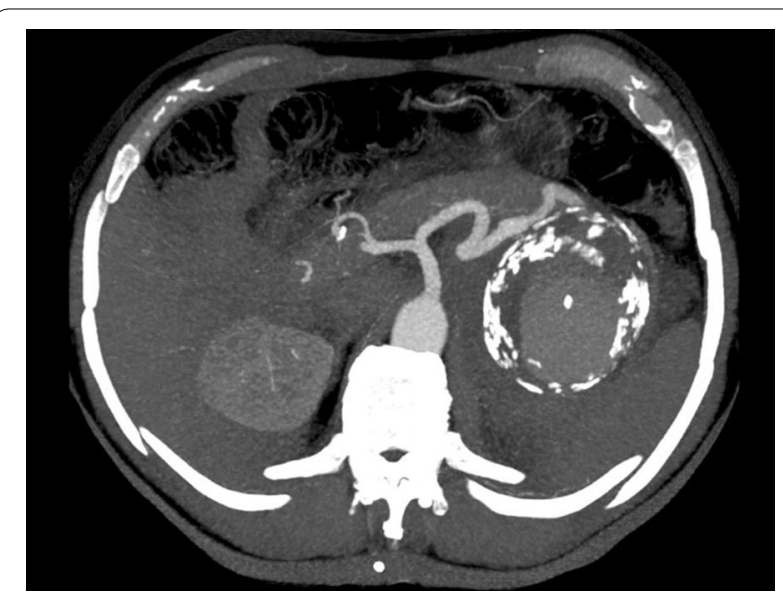

Fig. 3 Axial arterial phase contrast-enhanced MDCT. Maximal Intensity Projection view: Giant calcified aneurysm of the splenic artery

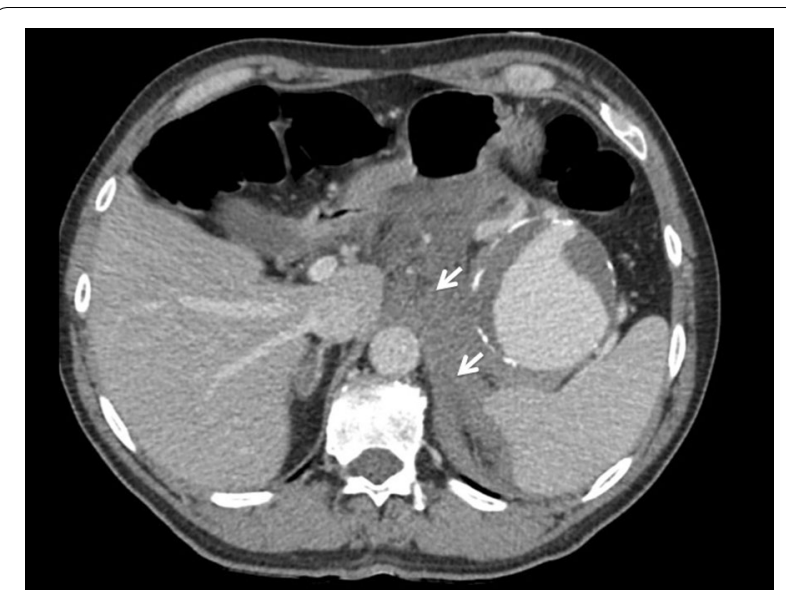

Fig. 4 Axial portal venous phase contrast-enhanced MDCT. Hemoretroperitoneum (white arrows)

5). A selective angiography (Fig. 6) was then performed under general anesthesia; a complete exclusion of the aneurysm was obtained with glue/lipiodol embolization. The post-intervention course was uneventful and the patient was discharged home 3 days later. The patient has remained free from any complications of the embolization 6 months after the procedure.

\section{Discussion}

We report the case of a patient presenting an acute fissuration of a previously asymptomatic giant splenic artery aneurysm detected by POCUS. Thanks to early detection, the aneurysm was embolized before full rupture and the patient was discharged home without complication. The occurrence of fissuration allowed an effective 


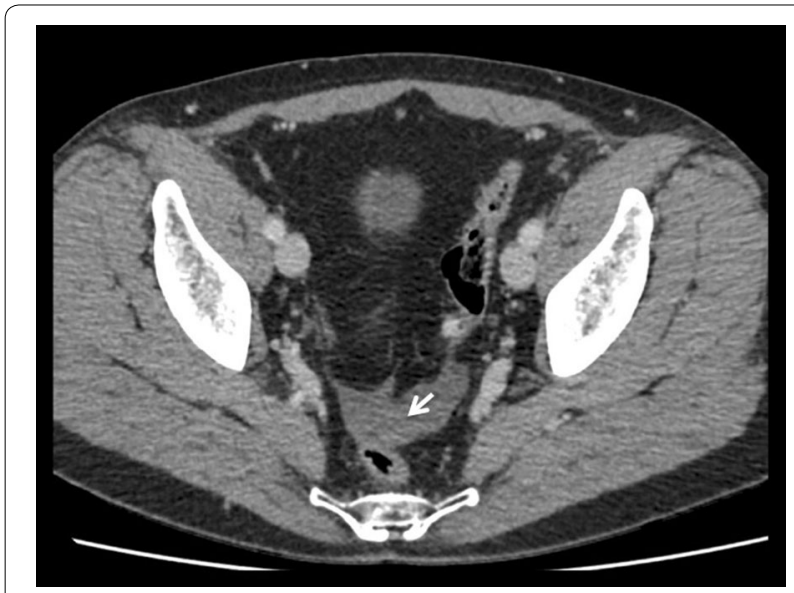

Fig. 5 Axial portal venous phase contrast-enhanced MDCT. Pelvic hemoperitoneum (white arrow)

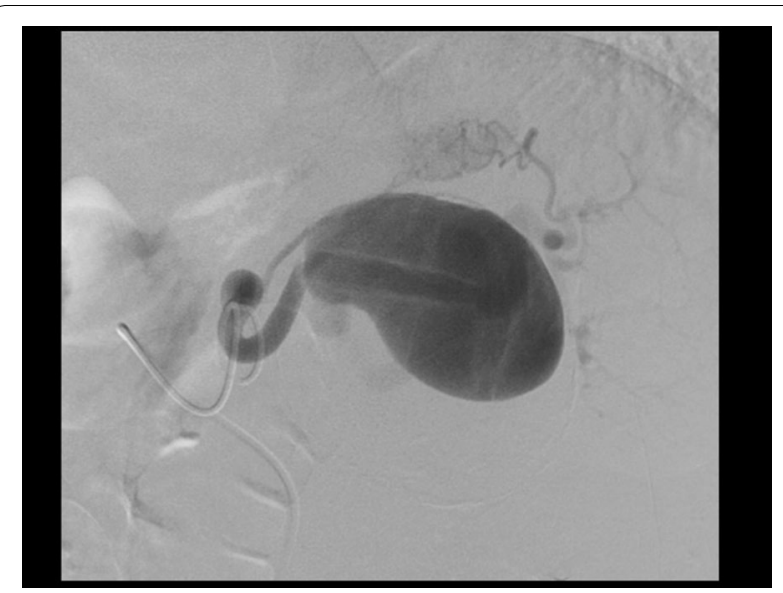

Fig. 6 Splenic angiography. Morphological aspect of the aneurysm

treatment before a catastrophic hemorrhagic shock. Although POCUS was used in other similar cases with SAA, the ultrasound was not conclusive and the diagnosis was made by CT-scan [2, 7]. To our knowledge, detection by POCUS of a fissuration episode has not been published. The "detection" of the SAA was done by POCUS in the case of Lo and Mok published in this journal [2], but the suspicion was of abdominal aortic aneurysm, so even if they detected it by POCUS, the correct and final diagnosis was made by CT-scan. There are many other similar cases [8] described in the literature, where POCUS showed an anechoic mass that sometimes was confused with a pancreatic cyst and others with an aortic aneurysm, and CT-scan was needed to reach the correct diagnosis [7, 9]. Rupture occurs in approximately $10 \%$ of SAA, especially when diameter exceeds
$2 \mathrm{~cm}$ [10], with a mortality rate of $10-25 \%$ [2]. Even if incidence and rupture rates are particularly increased in the third trimester of pregnancy [10], the risk is higher from the first trimester [11]. In all patients, endovascular embolization should be considered as the first-line treatment $[3,12]$ rather than surgery, but strong evidence is still lacking.

Abdominal pain accounted for 8 million ED visits in USA in 2006 [1]. Epigastric pain remains a challenging situation in particular in older patients. A pragmatic pathway could include a thorough physical exam, an ECG, appropriate biological workup, and POCUS.

\section{Conclusion}

Point-of-care ultrasound performances allow the trained Emergency Physician to rule in/out pericardial effusion [13], aortic aneurysms [14], and gallstones [15]. It is thus an invaluable tool and is recommended by the American College of Emergency Physicians [16].

\section{Additional files}

Additional file 1: Video 1. POCUS scan of the left upper quadrant of a patient presenting with epigastric pain. See the vascular mass located between spleen and kidney.

Additional file 2: Video 2. POCUS color Doppler scan of left upper quadrant in a patient presenting an epigastric pain. See the strong Doppler signal.

\section{Authors' contributions}

PLC realized POCUS, EF CT, and embolization; DT, PP and EB helped in casereport redaction. All authors read and approved the final manuscript.

\section{Author details}

1 Service des Urgences, CHU de Nantes, 44093 Nantes, France. ${ }^{2}$ Radiologie centrale, CHU de Nantes, Nantes, France.

\section{Acknowledgements}

None.

Competing interests

The authors declare that they have no competing interests.

\section{Availability of data and materials}

Not applicable.

\section{Consent for publication}

Consent to publish has been obtained from the patient.

\section{Ethics approval and consent to participate}

Written informed consent was obtained from the publication of this report and any accompanying images.

\section{Funding}

None.

\section{Publisher's Note}

Springer Nature remains neutral with regard to jurisdictional claims in published maps and institutional affiliations. 
Received: 14 December 2017 Accepted: 18 January 2018

Published online: 01 February 2018

\section{References}

1. Pitts SR, Niska RW, Xu J, Burt CW (2008) National hospital ambulatory medical care survey: 2006 emergency department summary. Natl Health Stat Rep 7:1-38

2. Lo WL, Mok KL (2015) Ruptured splenic artery aneurysm detected by emergency ultrasound - a case report. Crit Ultrasound J 7:9. https://doi. org/10.1186/s13089-015-0026-4

3. Akbulut S, Otan E (2015) Management of giant splenic artery aneurysm. Medicine (Baltimore) 94:e1016. https://doi.org/10.1097/ MD.0000000000001016

4. Stanley JC, Fry WJ (1974) Pathogenesis and clinical significance of splenic artery aneurysms. Surgery 76:898-909

5. Al-Habbal Y, Christophi C, Muralidharan V (2010) Aneurysms of the splenic artery-a review. Surgeon 8:223-231

6. Liu C-F, Kung C-T, Liu B-M et al (2007) Splenic artery aneurysms encountered in the ED: 10 years' experience. Am J Emerg Med 25:430-436. https://doi.org/10.1016/j.ajem.2006.08.017

7. Iyanaga M, Watts S, Kasai T (2010) A patient with splenic artery aneurysm rupture and the importance of rapid sonography in the ED. Emerg Med Int. https://doi.org/10.1155/2010/893606

8. Davis T, Minardi J, Knight J et al (2015) Ruptured splenic artery aneurysm: rare cause of shock diagnosed with bedside ultrasound. West J Emerg Med 16:762-765. https://doi.org/10.5811/westjem.2015.7.25934
9. Abdulrahman A, Shabkah A, Hassanain M, Aljiffry M (2014) Ruptured spontaneous splenic artery aneurysm: a case report and review of the literature. Int J Surg Case Rep 5:754-757. https://doi.org/10.1016/j. ijscr.2014.08.021

10. Sadat U, Dar O, Walsh S, Varty K (2008) Splenic artery aneurysms in pregnancy-a systematic review. Int J Surg 6:261-265. https://doi. org/10.1016/j.ijsu.2007.08.002

11. Groussolles M, Merveille M, Alacoque X et al (2011) Rupture of a splenic artery aneurysm in the first trimester of pregnancy. J Emerg Med 41:e13e16. https://doi.org/10.1016/j.jemermed.2010.04.023

12. Yamamoto S, Hirota S, Maeda H et al (2008) Transcatheter coil embolization of splenic artery aneurysm. Cardiovasc Interv Radiol 31:527-534. https://doi.org/10.1007/s00270-007-9237-9

13. Labovitz AJ, Noble VE, Bierig M et al (2010) Focused cardiac ultrasound in the emergent setting: a consensus statement of the American Society of Echocardiography and American College of Emergency Physicians. J Am Soc Echocardiogr 23:1225-1230. https://doi.org/10.1016/j. echo.2010.10.005

14. Kuhn M, Bonnin RLL, Davey MJ et al (2000) Emergency department ultrasound scanning for abdominal aortic aneurysm: accessible, accurate, and advantageous. Ann Emerg Med 36:219-223. https://doi.org/10.1067/ mem.2000.108616

15. Kendall JL, Shimp RJ (2001) Performance and interpretation of focused right upper quadrant ultrasound by emergency physicians. J Emerg Med 21:7-13. https://doi.org/10.1016/S0736-4679(01)00329-8

16. ACEP (2016) Ultrasound guidelines: emergency, point-of-care, and clinica ultrasound guidelines in medicine. https://www.acep.org/Clinical---Practice-Management/Ultrasound/. Accessed 23 Jan 2018

\section{Submit your manuscript to a SpringerOpen ${ }^{\odot}$ journal and benefit from:}

- Convenient online submission

- Rigorous peer review

- Open access: articles freely available online

- High visibility within the field

- Retaining the copyright to your article

Submit your next manuscript at $\boldsymbol{\nabla}$ springeropen.com 